\title{
Rancang Bangun Sistem Jaringan Nirkabel untuk Pemantauan Penggunaan Air Pelanggan PDAM
}

\author{
Sean Satya Henura*1,Triyogatama Wahyu Widodo ${ }^{2}$ \\ ${ }^{1}$ Prodi S1 Elektronika dan Instrumentasi; Sekip Utara Bulaksumur \\ ${ }^{2}$ Jurusan Ilmu Komputer dan Elektronika, FMIPA UGM, Yogyakarta \\ e-mail: *1 sean.sahenura@gmail.com, ${ }^{2}$ yogatama@mail.ugm.ac.id
}

\begin{abstract}
Abstrak
Penelitian ini membuat rancang bangun sistem untuk memantau data penggunaan air pelanggan PDAM melalui jaringan nirkabel. Dalam skala kecil, sistem ini diperuntukkan bagi pelanggan yang tidak memiliki akses terhadap riwayat pemakaian airnya, sehingga mempersulit pengelolaannya. Pada skala yang lebih besar, sistem ini menjadi solusi atas permasalahan perusahaan yang dalam mengumpulkan data pengunaan air pelanggannya masih perlu mendatangi satu persatu rumah mereka setiap bulan.

Sistem ini dibuat dengan memasang komponen pada meteran air yang mampu mengirimkan data perhitungannya ke sebuah server untuk disimpan dalam database MySQL. Sedangkan untuk pemantauannya digunakan suatu aplikasi pada smartphone android yang dapat meminta kepada server data-data pada waktu yang diinginkan para pengguna. Data dikirimkan menggunakan protokol HTTP melalui jaringan internet, yang didapat dari modul Ethernet pada meteran air, dan koneksi seluler atau wifi pada smartphone android..

Hasil yang diperoleh dari pengujian menunjukkan bahwa secara fungsional, pemantauan dapat dilakukan dengan baik. Kelima protokol yang diuji terbukti dapat bekerja sesuai dengan rancangan yang diharapkan dengan kisaran bandwith total yang diperlukan atas data-data yang dikirim dan diterima mulai dari meteran air hingga smartphone ialah 1,046 KBps. Ini menunjukkan bahwa pengiriman data dari meteran air dan penyimpanan data di database server juga berhasil dilakukan.
\end{abstract}

Kata kunci-HTTP, Android, Layanan berbasis lokasi, Pemantauan

This study builds system prototype to monitor customer's usage of water provided by PDAM through wireless network. The system were made to help customers who don't have access to their water usage history, preventing them to properly manage it. On a bigger scale, this system could be solution to the company problem on collecting their customer usage data which have to be done by visiting each customer's house monthly.

This system was made by attaching components to water meter that capable of sending meter data to a server to be saved on MySQL database. For usage monitoring, an app made for android smartphone that sends request to server asking for usage data of certain time wanted by the user was used. The data were sent using HTTP protocol on internet connectivity gained from Ethernet module on water meter part and either cellular connection or Wi-Fi on android smartphone part.

Results gotten from the conducted tests show that functional-wise, the monitoring can be done accurately using $1.046 \mathrm{KBps}$ bandwith during process. Of the 5 protocol tested, all proved to be working as designed. The tests show that data sending of water meter and data saving on server database are working.

Keywords—HTTP, Android, Location based service, Monitoring 


\section{PENDAHULUAN}

$\mathrm{H}^{3}$ ingga saat ini pihak PDAM masih mengumpulkan data penggunaan air pelanggannya dengan memantau secara langsung meteran air pada pipa pelanggan di setiap rumah setiap bulannya. Disamping itu juga para pelanggan belum memiliki akses terhadap detil pemakaian air mereka selain dari jumlah volume dan tagihan bulanan. Dengan membuat pengambilan data air yang dapat dilakukan dari jauh, PDAM dapat melakukan pengambilan data dalam rentang waktu yang jauh lebih kecil dari bulanan. Dengan itu data pemakaian pelanggan secara detil akan dimiliki oleh PDAM dan memungkinkan untuk diakses oleh para pelanggannya.

Untuk melakukan ini dibutuhkan jaringan yang luas, sehingga sistem ini akan dijalankan diatas jaringan nirkabel. Pemantauan dan pengambilan data pelanggan oleh perusahaan semacam ini pernah dilakukan oleh [1], namun terhadap data pemakaian listrik pelanggan oleh PLN dan berhasil dilakukan. Maka dari sini dibutuhkan komunikasi server klien, dimana dibutuhkan 2 buah klien yang salah satunya akan mengirimkan data perhitungan pemakaian air, dan yang lainnya dapat meminta data pemakaian air di waktu tertentu. Klien yang mengirimkan data perhitungan penggunaan air terletak pada meteran air itu sendiri, sedangkan klien lainnya adalah smartphone sehingga pengguna dapat dengan mudah memantau penggunaan air mereka. Seluruh data masuk melalui server terlebih dahulu seperti ditunjukkan oleh Gambar 1, dan server tersebut dikelola oleh pihak PDAM. Sedangkan pemantauan untuk PDAM sendiri pernah dilakukan oleh [2] dengan pengiriman data melalui media SMS untuk pemantauan oleh pengguna, namun masih belum diperuntukkan untuk jaringan besar PDAM.

Selain itu penting juga agar data dapat dibagi berdasarkan wilayahnya karena cakupan sistem ini bisa sangat luas. Seperti yang dilakukan oleh [3] yang mengukur kadar CO2 dan memetakannya berdasarkan lokasi atau wilayah menggunakan GPS. Dengan mengaplikasikan cara ini, maka sistem ini dapat memetakan persebaran penggunaan air di wilayah cakupan operasi PDAM. Pengambilan lokasi akan menggunakan GPS yang umumnya sudah tersedia di smartphone.

\section{METODE PENELITIAN}

\subsection{Rancangan Kerja Sistem}

Sistem ini dapat menangani pemantauan data secara berkala, dimulai dari meteran air hingga sampai ke tangan pengguna. Maka akan ada dua bagian sistem dari satu sistem besar pemantauan ini: bagian yang memproses agar data tersebut dapat dipantau, yaitu sistem pada meteran, dan bagian yang dapat memantau data tersebut secara mobile, yang pada sistem ini diwakili oleh penggunaan smartphone.

Data perlu diletakkan di suatu server yang diperuntukkan untuk dikelola oleh PDAM. Sebagai tempat terpusatnya data, penyimpanan data dari hitungan meteran akan diambil alih server. Begitu juga permintaan pengguna untuk meminta data penggunaannya melalui smartphone juga dilayani oleh server sebagai tempat data tersebut berada. Agar data dari meteran seorang pengguna dapat diambil oleh smartphone pengguna tersebut, dan bukan data pengguna lainnya, maka akan ada akun dan id spesifik yang menghubungkan keduanya. Untuk mendapatkan akun tersebut pengguna harus melakukan otentikasi semacam registrasi dan login. Berhubung sistem ini terbagi menjadi 2 bagian yang terpisah, maka otentikasi harus dilakukan pada kedua bagian sistem tersebut (meteran dan smartphone),

Pada penelitian ini, rancangan sistem meteran diwakili oleh arduino, sedangkan sistem pada smartphone dijalankan diatas platform android. Kedua bagian ini harus dapat berkomunikasi dengan server secara nirkabel. Oleh karena itu akan digunakan Ethernet shield agar arduino dapat terhubung ke jaringan internet. Fitur koneksi nirkabel sudah ada pada smartphone, baik itu langsung dari jaringan provider seluler maupun wifi. Perhitungan debit air 
pada meteran akan dilakukan menggunakan simulasi untuk menjaga fokus penelitian tetap pada pendistribusian datanya. Diagram kerja keseluruhan sistem ini ditunjukkan oleh Gambar 1

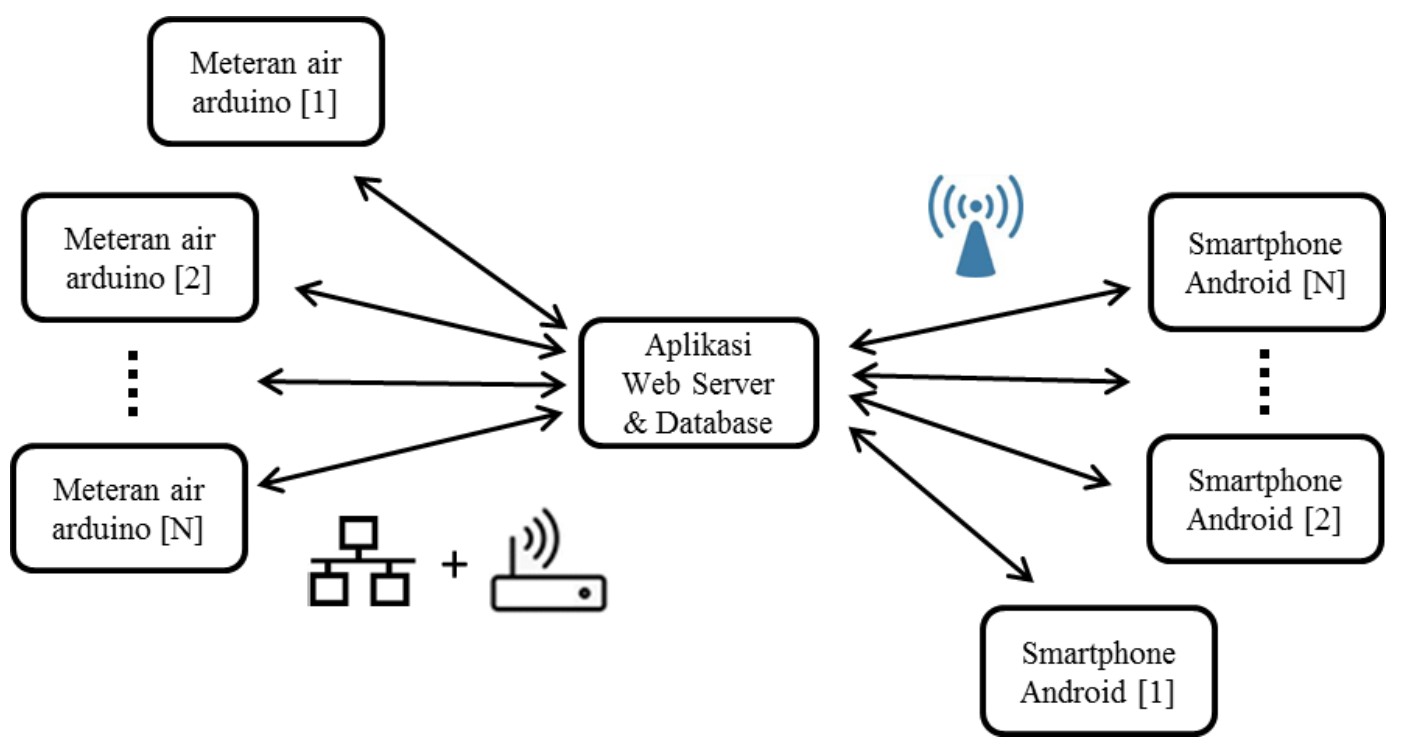

Gambar 1 Diagram kerja sistem

\section{$2.2 \quad H T T P$}

HTTP (Hypertext Transfer Protocol) yang digunakan dalam sistem ini ialah sebuah aturan untuk mentransfer file, bisa berupa teks, gambar, suara, video atau file multimedia lainnya, ke web internet. Komunikasi antara client dan server terjadi via suatu pasangan requestresponse. Client membuat sebuah pesan HTTP request yang akan dilayani server dengan balasan berupa HTTP response. Web browser yang biasa digunakan pengguna ialah sebuah client HTTP yang mengirim request ke server. Ketika pengguna browser membuka halaman dengan mengetik pada url atau mengklik sebuah link hypertext, browser membuat sebuah request HTTP dan mengirimnya ke alamat IP yang ditunjuk oleh url. Server menerima request tersebut dan mengirim kembali file yang diminta, atau yang berhubungan.

Pada client meteran air, protokol digunakan dari client untuk mengirim data penggunaan user ke server dengan balasan konfirmasi dari server, sedangkan pada client smartphone, protokol digunakan untuk mengirim request ke server dan mengirim balasan data yang diminta kembali ke client.

\subsection{Android Location API}

Android menyediakan beberapa kelas yang berhubungan dengan pencarian lokasi yang mengatur terjadinya alur request pencarian lokasi di android pada Gambar 2 Diantaranya sebagai berikut:

- Location Manager: Kelas ini memberi akses ke layanan lokasi.

- Location Provider: Kelas ini memberi update berkala mengenai posisi geografis

- Location Listener: Kelas ini akan memanggil sebuah method ketika lokasi berubah. Objek kelas ini harus dihubungkan ke Location Manager.

Criteria: Kelas ini dapat memilih Location Provider yang cocok tergantung dari set property yang diinginkan [4]. 
Android juga memberi suatu API untuk akses ke google maps. Dengan komponen ini kita dapat menunjukkan posisi yang didapat ke peta, atau mengambil alamat darinya. Proses ini dinamakan reverse-geocoding. Proses sebaliknya, geocoding, adalah menggunakan alamat untuk mencari koordinatnya. Proses geocoding ini yang akan diaplikasikan pada sistem untuk mengubah data koordinat dari GPS smartphone menjadi nama lokasi.

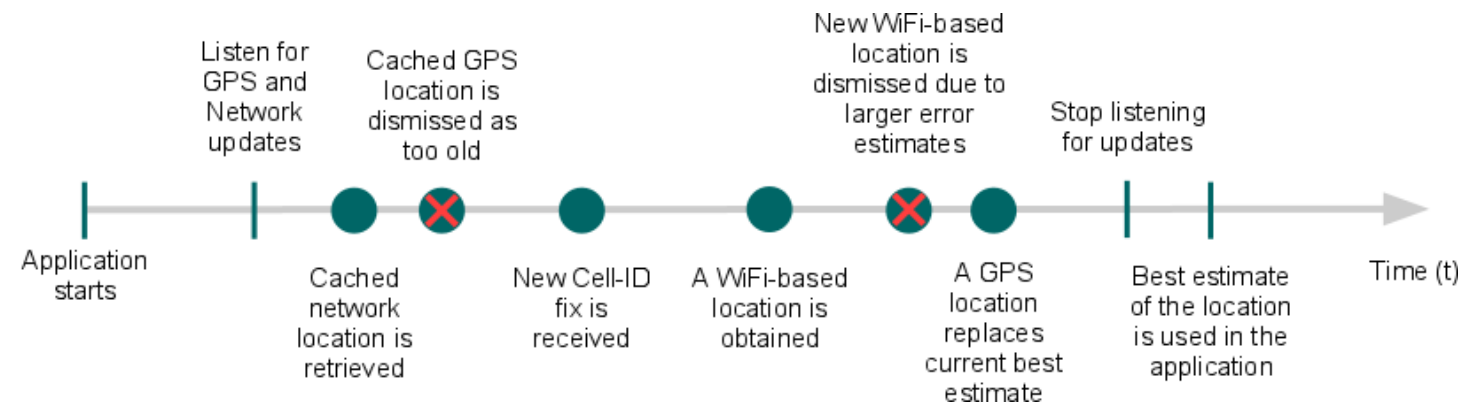

Gambar 2 Alur pengambilan lokasi pada sistem android

\section{$2.4 \quad$ Database}

Database digunakan untuk dapat menyimpan data secara terstruktur, yang memudahkan dalam pencarian data dan pengelolaannya. Database pada server yang menggunakana MySQL digunakan untuk menyimpan data pengguna dan data pemakaian mereka.

\section{HASIL DAN PEMBAHASAN}

\subsection{Fungsionalitas Pemantauan}

Rancang bangun sistem ini memiliki dua buah fungsi utama. Salah satunya ialah kemampuan untuk mengoleksi data pemakaian air para pelanggan PDAM dari meteran air di pipa, yang dalam penelitian ini diwujudkan dengan simulasi menggunakan arduino, ke server. Fungsi lainnya ialah memberi akses agar data tersebut dapat juga dipantau oleh pelanggan melalui smartphone android masing-masing.

Setiap pelanggan dapat terlebih dahulu melakukan registrasi akun agar datanya terdaftar di server. Setelah registrasi, maka pelanggan dapat melakukan login di meteran arduinonya maupun di smartphone androidnya. Pada meteran arduino, setelah proses login berhasil, maka setiap jamnya, hasil perhitungan jumlah volume air yang keluar akan dikirim ke server dan disimpan di database server. Data-data penggunaan air pelanggan tersebut yang berhasil disimpan di dalam database server dapat dipantau oleh mereka sendiri dengan melakukan login pada aplikasi di smartphone android mereka masing-masing. Hasil tampilan yang muncul pada pemantauan di smartphone ditunjukkan pada Gambar 3a. Sedangkan pada Gambar 3b ditunjukkan grafik pemakaian pribadi pelanggan tersebut (warna merah), yang dibandingkan dengan rerata pemakaian air wilayah di kota pelanggan itu sendiri (warna biru). Pengambilan lokasi pelanggan menggunakan gps pada smartphone dilakukan pada saat registrasi, atau bisa juga dilakukan setelah login. 


\begin{tabular}{l} 
9ि: Home Screen \\
\hline $2014-7-21$ Logout (user1) daily \\
\hline $0 \mathrm{am}$ \\
$173(161)$ \\
$1 \mathrm{am}$ \\
$158(133)$ \\
$2 \mathrm{am}$ \\
$230(198)$ \\
$3 \mathrm{am}$ \\
$172(230)$ \\
$4 \mathrm{am}$ \\
$444(457)$ \\
\end{tabular}

(a)

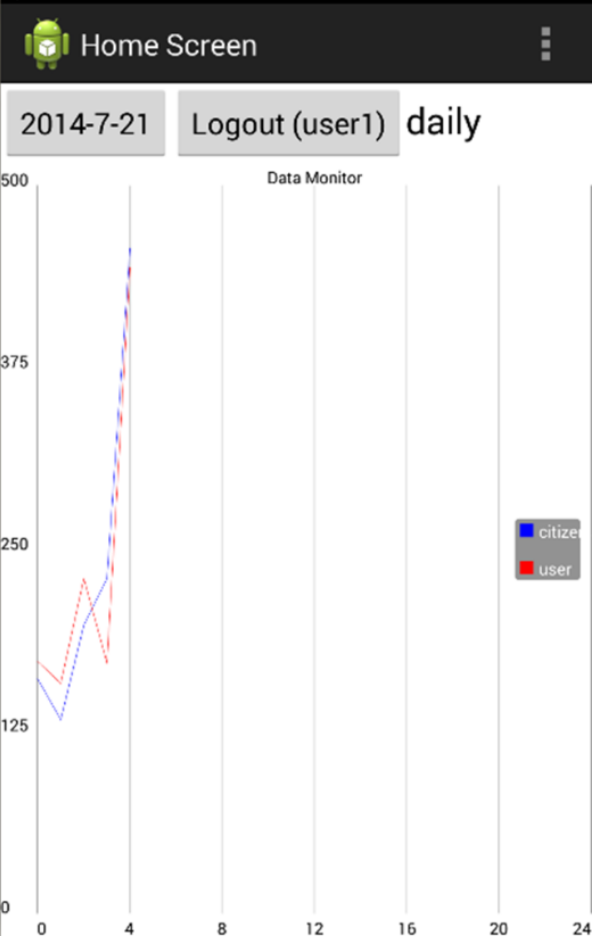

(b)

Gambar 3 Tampilan hasil pemantauan pada aplikasi smartphone

Pengujian yang dilakukan mencakup tahapan yang diperlukan oleh pengguna dari awal registrasi hingga sampai dapat dilakukan pemantauan. Ilustrasi tahap pengujian tersebut digambarkan pada Gambar 4. Dibuat suatu skenario dimana ada 5 sampel pelanggan (A, B, C, $\mathrm{D}$, dan E) dari 2 kelompok lokasi kota yang berbeda. Pengujian dimulai dengan melakukan registrasi setiap pengguna melalui smartphone di suatu lokasi di bagian kota yang sudah ditentukan. Setelah registrasi sukses, maka dilakukan login pada sistem meteran arduino,

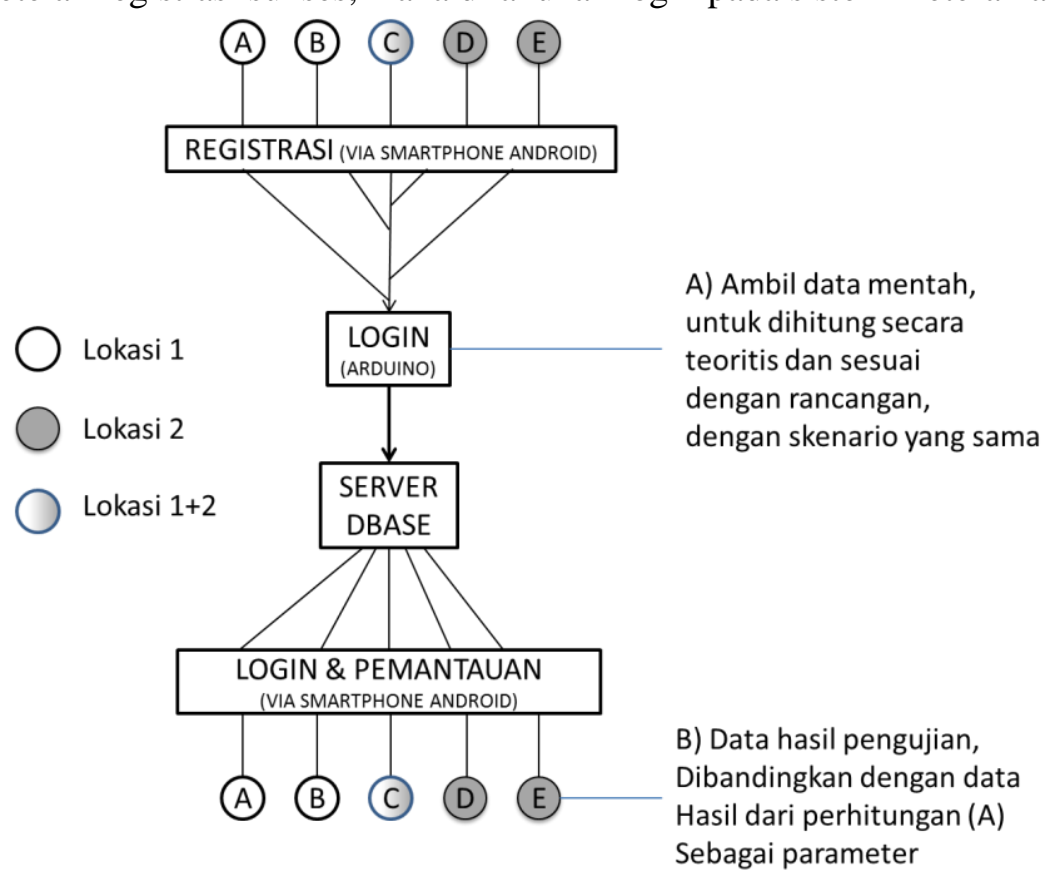

Gambar 4 Tahap pengujian fungsionalitas 
sehingga pengiriman data ke server dimulai. Pada setiap pengiriman data ke server, data yang terkirim melalui akun setiap pelanggan dicatat untuk nantinya dibandingkan dengan hasil pemantauan di smartphone. Namun ada perlakuan khusus pada salah satu pelanggan (pelanggan C), dimana data lokasinya diubah pada suatu waktu di pertengahan proses pengiriman tersebut. Tahap terakhir yang dilakukan ialah login pada smartphone dan melakukan pemantauan data melalui akun masing-masing pelanggan tersebut.

Hasil yang terpampang pada aplikasi di smartphone tersebut dibandingkan dengan perhitungan yang dilakukan secara teoritis, dari data yang dicatat ketika meteran mengirimkan data ke server. Perbandingan dilakukan pada data penggunaan pribadi maupun data penggunaan rerata wilayah. Tabel 1 menunjukkan data setiap jam milik setiap pelanggan yang dikirim dan disimpan ke server. Pada bagian ini, data yang diambil secara teoritis sama dengan data yang terpampang di pemantauan. Data ini menjadi data mentah yang akan diolah untuk dijadikan parameter pada tahap berikutnya. Dari data ini dihitung rerata wilayah untuk masing-masing interval harian maupun bulanan.

Tabel 1 Data pribadi pelanggan untuk interval harian

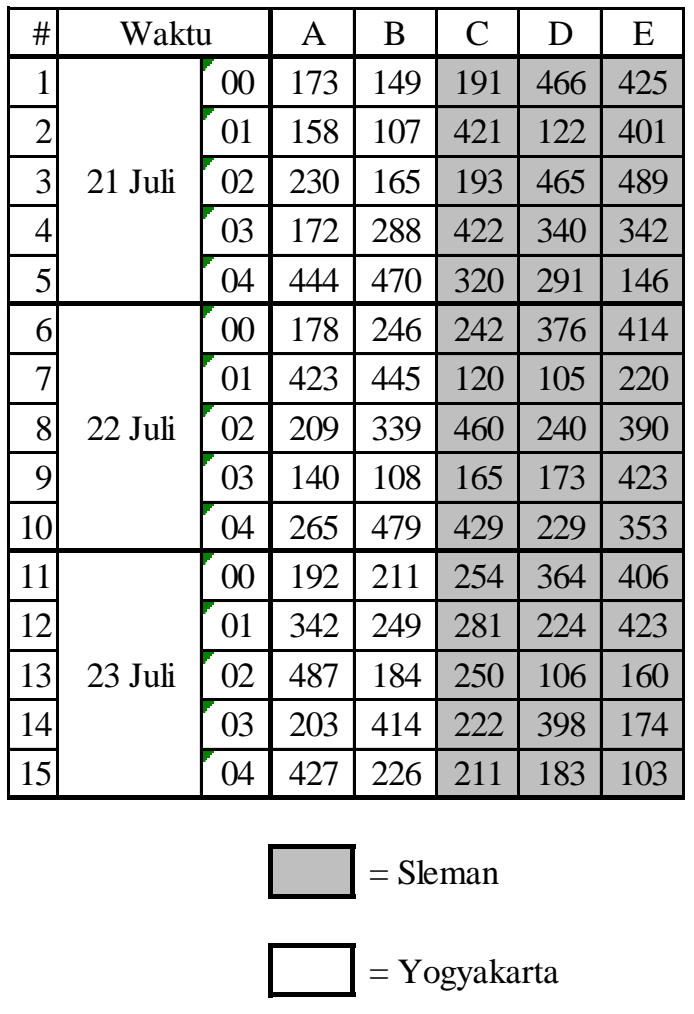

\begin{tabular}{|c|c|c|c|c|c|c|c|}
\hline$\# 1$ & \multicolumn{2}{|c|}{ Waktu } & A & B & $\mathrm{C}$ & D & E \\
\hline & \multirow{5}{*}{$24 \mathrm{Juli}$} & 00 & 229 & 336 & 395 & 289 & 489 \\
\hline & & 01 & 140 & 263 & 251 & 207 & 269 \\
\hline & & 02 & 312 & 461 & 103 & 203 & 383 \\
\hline & & 03 & 403 & 146 & 122 & 427 & 128 \\
\hline & & 04 & 469 & 467 & 430 & 351 & 170 \\
\hline & \multirow{5}{*}{$25 \mathrm{Juli}$} & 00 & 209 & 181 & 449 & 232 & 385 \\
\hline & & 01 & 457 & 392 & 489 & 181 & 191 \\
\hline & & 02 & 460 & 178 & 475 & 451 & 385 \\
\hline & & 03 & 233 & 219 & 345 & 472 & 477 \\
\hline & & 04 & 399 & 269 & 164 & 165 & 416 \\
\hline & \multirow{5}{*}{26 Juli } & 00 & 378 & 250 & 119 & 361 & 127 \\
\hline & & 01 & 316 & 169 & 425 & 298 & 247 \\
\hline & & 02 & 235 & 277 & 262 & 433 & 310 \\
\hline & & 03 & 397 & 492 & 320 & 106 & 180 \\
\hline & & 04 & 326 & 158 & 245 & 335 & 317 \\
\hline & \multirow{5}{*}{ 27Juli } & 00 & 412 & 293 & 409 & 137 & 131 \\
\hline & & 01 & 167 & 201 & 290 & 111 & 204 \\
\hline & & 02 & 310 & 177 & 240 & 493 & 366 \\
\hline & & 03 & 133 & 428 & 373 & 380 & 257 \\
\hline & & 04 & 279 & 423 & 444 & 356 & 414 \\
\hline
\end{tabular}

Dari data pada Tabel 1 dapat dilakukan perhitungan teoritis (perhitungan diluar sistem yang sudah dibuat) untuk mengetahui rerata wilayah hariannya dan nantinya menghitung pemakaian bulanan tiap pelanggan dan rerata wilayah bulanannya. Tabel 2 menunjukkan data rerata wilayah dalam interval harian, dimana masih didapat data pada pemantauan di smartphone cocok dengan data perhitungan teoritis. Pada bagian interval harian ini belum terlihat pengaruh dari perpindahan lokasi pelanggan $\mathrm{C}$ yang dilakukan saat pengujian terhadap hasil perhitungan rerata wilayah, dikarenakan interval harian masih menunjukkan data setiap jam. Namun pada Tabel 2 terlihat bahwa pada tanggal 24 juli, ada waktu dimana data pelanggan $\mathrm{C}$ mengalami perpindahan lokasi. 
Tabel 2 Data rerata pelanggan di setiap wilayah interval harian

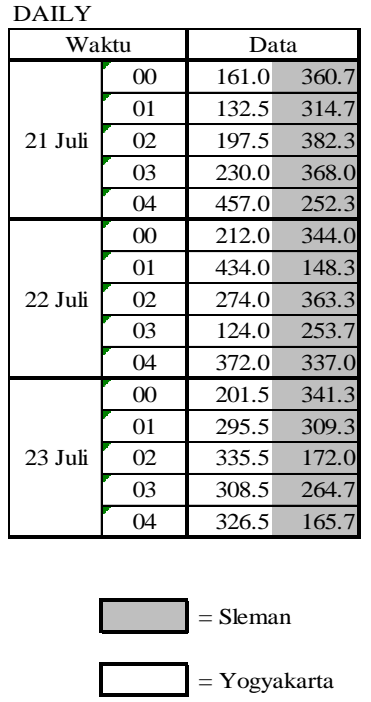

\begin{tabular}{|c|c|c|c|}
\hline \multicolumn{2}{|c|}{ Waktu } & \multicolumn{2}{|c|}{ Data } \\
\hline \multirow{5}{*}{24 Juli } & 00 & 282.5 & 391.0 \\
\hline & 01 & 218.0 & 238.0 \\
\hline & 02 & 292.0 & 293.0 \\
\hline & 03 & 223.7 & 277.5 \\
\hline & 04 & 455.3 & 260.5 \\
\hline \multirow{5}{*}{25 Juli } & 00 & 279.7 & 308.5 \\
\hline & 01 & 446.0 & 186.0 \\
\hline & 02 & 371.0 & 418.0 \\
\hline & 03 & 265.7 & 474.5 \\
\hline & 04 & 277.3 & 290.5 \\
\hline \multirow{5}{*}{26 Juli } & 00 & 249.0 & 244.0 \\
\hline & 01 & 303.3 & 272.5 \\
\hline & 02 & 258.0 & 371.5 \\
\hline & 03 & 403.0 & 143.0 \\
\hline & 04 & 243.0 & 326.0 \\
\hline \multirow{5}{*}{ 27Juli } & 00 & 371.3 & 134.0 \\
\hline & 01 & 219.3 & 157.5 \\
\hline & 02 & 242.3 & 429.5 \\
\hline & 03 & 311.3 & 318.5 \\
\hline & 04 & 382.0 & 385.0 \\
\hline
\end{tabular}

Pada Tabel 3, dapat dilihat pengaruh dari perlakuan yang dilakukan pada pelanggan C saat pengujian karena interval bulanan menunjukkan total penggunaan setiap harinya. Dengan diubahnya lokasi pada waktu tertentu, yaitu pada suatu waktu di tanggal 24 juli, maka rerata wilayah pada satu hari itu mengalami transisi sehingga tidak sesuai dengan rerata wilayah manapun. Namun perhitungan secara teoritis membuktikan bahwa hasil perhitungan tersebut sudah tepat. Selain dari tanggal itu, karena tidak ada perpindahan lokasi, maka rerata penggunaannya sama dengan rerata wilayah ketika sebelum maupun sesudah perpindahan lokasi.

Tabel 3 Data rerata bulanan di setiap wilayah

MONTHLY

\begin{tabular}{|l|c|c|c|c|c|}
\hline Waktu & \multicolumn{2}{|c|}{ Data Wilayah } & User A & User C & User D \\
\hline 21 Juli & 1178.0 & 1678.0 & 1178.0 & 1678.0 & 1678.0 \\
\hline 22 Juli & 1416.0 & 1446.3 & 1416.0 & 1446.3 & 1446.3 \\
\hline 23 Juli & 1467.5 & 1253.0 & 1467.5 & 1253.0 & 1253.0 \\
\hline 24 Juli & 1471.5 & 1460.0 & 1471.5 & $\mathbf{1 5 8 0 . 0}$ & 1460.0 \\
\hline 25 Juli & 1639.7 & 1677.5 & 1639.7 & 1639.7 & 1677.5 \\
\hline 26 Juli & 1456.3 & 1357.0 & 1456.3 & 1456.3 & 1357.0 \\
\hline 27 Juli & 1526.3 & 1424.5 & 1526.3 & 1526.3 & 1424.5 \\
\hline
\end{tabular}

$\square=$ Sleman

$\square=$ Yogyakarta

\subsection{Protokol}

Beberapa protokol penting yang digunakan ialah protokol untuk login/registrasi, request pemantauan ke server dan pengambilan lokasi melalui smartphone, dan pengiriman data volume air perjam dari meteran arduino. Keberhasilan uji fungsionalitas menunjukkan bahwa protokol berfungsi dengan baik ketika setiap request dari client berhasil dilaksanakan oleh server. Maka dilakukan pengujian untuk menunjukkan jalannya protokol ketika terdapat response dari server yang menunjukkan kegagalan.

Pada login arduino, jika data login tidak ditemukan, maka sistem meteran arduino akan meminta ulang user untuk mengisi data login (username dan password). Pada android juga dilakukan hal yang sama. Pada bagian pengambilan lokasi dengan smartphone, apabila penentuan lokasi mengalami halangan sehingga nama wilayah tidak bisa diambil, maka akan ditampilkan pop-up message yang menandai bahwa lokasi tidak bisa ditemukan, begitu pula 
dengan pemantauan ketika data tidak ditemukan pada waktu tersebut. Untuk meteran arduino, jika data gagal disimpan di server setelah beberapa kali percobaan, maka data akan disimpan sementara di EEPROM arduino, dan akan dicoba untuk dikirim kembali pada jam berikutnya setelah data diwaktu tersebut berhasil dikirim. Jika data di EEPROM berhasil terkirim, maka data tersebut akan dihapus. Namun jika masih belum berhasil, maka data tersebut tetap disimpan. Gambar 5 menunjukkan sampel beberapa request yang terkirim dan response yang jika diterima akan membuat sistem melakukan hal yang sudah disebutkan di atas, dimana bagian 6a menunjukkan protokol antara client android-server, sedangkan $6 \mathrm{~b}$ menunjukkan antara client arduino-server.

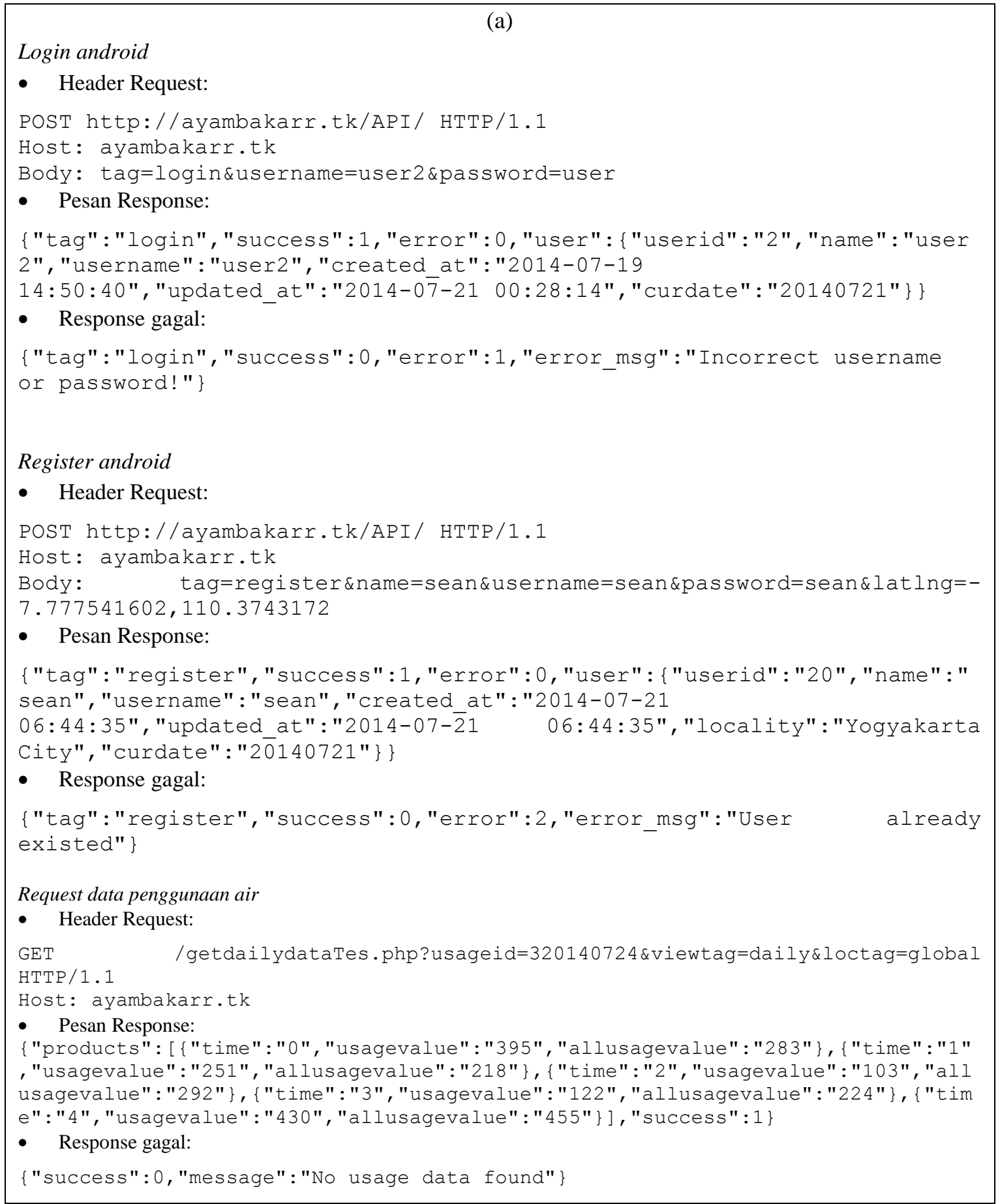

IJEIS Vol. 5, No. 2, October 2015 : 155 - 164 
Login arduino

(b)

- Format Request:

GET /API/?tag=login\&username=user5\&password=user HTTP/1.1

- Pesan Response:

$<512030>$

- Response gagal:

$<\mathrm{f} 0>$

Update data arduino

- Format Request:

GET /API / ?tag=update\&userid=12\&value=122\&time=212 HTTP/1.1

- Pesan Response:

$<$ s 03>

- Response gagal:

$<e 0>$ atau $\langle e 1>$

Gambar 5 Daftar protokol android-server dan arduino-server

\subsection{Bandwith}

Dengan menghitung setiap byte yang terkirim dan diterima dalam setiap alur requestresponse, serta menghitung response time-nya dapat dihitung estimasi bandwith yang digunakan pada setiap komunikasi. Tabel 4 menunjukkan data byte dan response time dari beberapa keadaan (Test case). Sedangkan Tabel 5 menunjukkan hasil perhitungan estimasi bandwith-nya. Penjelasan test case no.1 dan 2 ialah request pemantauan harian dan bulanan melalui smartphone dengan balasan data penuh 24 jam dan 30 hari. Sedangkan kasus no. 3 dan 4 tidak ditemukan data di database sehingga tidak ada balasan. Test case no. $5-8$ menunjukkan pengiriman data meteran arduino dengan variasi jumlah byte yang dikirim, dimana byte yang dikirim meliputi gabungan data userid, dan data volume penggunaan air.

Tabel 4 Daftar jumlah byte dan response time

\begin{tabular}{|l|l|c|c|c|c|c|c|c|}
\hline$\#$ & \multicolumn{1}{|c|}{ Test Case } & $\begin{array}{c}\text { Time Avg. } \\
\text { (s) }\end{array}$ & Min. (s) & $\begin{array}{c}\text { Max 99\% } \\
\text { (s) }\end{array}$ & Max. (s) & $\begin{array}{c}\text { Avg. Sent } \\
\text { bytes }\end{array}$ & $\begin{array}{c}\text { Avg. } \\
\text { Received } \\
\text { bytes (KB) }\end{array}$ & $\begin{array}{c}\text { Avg. } \\
\text { Response } \\
\text { Body size } \\
\text { (B) }\end{array}$ \\
\hline 1 & daily full response & 0.586 & 0.491 & 0.552 & 2.269 & 125 & 601.86 & 395 \\
\hline 2 & monthly full response & 0.573 & 0.493 & 0.551 & 1.67 & 127 & 689.62 & 308 \\
\hline 3 & daily zero response & 0.584 & 0.501 & 0.548 & 2.327 & 125 & 347.86 & 54 \\
\hline 4 & monthly zero response & 0.598 & 0.482 & 0.569 & 2.018 & 127 & 347.48 & 53 \\
\hline 5 & Update 7 digit (min) & 0.542 & 0.47 & 0.536 & 0.829 & 112 & 307.86 & 13 \\
6 & Update 8 digit & 0.537 & 0.472 & 0.53 & 0.877 & 113 & 308.62 & 13 \\
\hline 7 & Update 10 digit & 0.559 & 0.478 & 0.526 & 2.175 & 115 & 309 & 14 \\
8 & Update 14 digit (max) & 0.581 & 0.487 & 0.552 & 2.03 & 120 & 307.86 & 13 \\
\hline
\end{tabular}

Tabel 5 Daftar perhitungan estimasi bandwith

\begin{tabular}{|l|l|c|c|c|}
\hline \# & \multicolumn{1}{|c|}{ Test Case } & $\begin{array}{c}\text { Bandwith } \\
\text { (kB/s) }\end{array}$ & $\begin{array}{c}\text { Time Avg. } \\
\text { (s) }\end{array}$ & $\begin{array}{c}\text { Avg. Sent- } \\
\text { received } \\
\text { bytes (kB) }\end{array}$ \\
\hline 1 & daily full response & 0.602 & 0.586 & 0.727 \\
\hline 2 & monthly full response & 0.690 & 0.573 & 0.817 \\
\hline 3 & daily zero response & 0.348 & 0.584 & 0.473 \\
\hline 4 & monthly zero response & 0.347 & 0.598 & 0.474 \\
\hline 5 & Update 7 digit (min) & 0.308 & 0.542 & 0.420 \\
7 & Update 8 digit & 0.309 & 0.537 & 0.422 \\
\hline 8 & Update 10 digit & 0.309 & 0.559 & 0.424 \\
\hline
\end{tabular}


Dari data pada Tabel 5 maka didapatkan rata-rata pemakaian bandwith setiap pemantauan yang dilakukan melalui smartphone android ialah $0.623 \mathrm{~KB} / \mathrm{s}$ (test case 14).Sedangkan update pada meteran arduino membutuhkan rata-rata bandwith $0.423 \mathrm{~KB} / \mathrm{s} \mathrm{per}$ pengiriman (test case 5-8).Maka ketika server dengan kapasitas bandwith 10Mbps (Megabits per second) digunakan, server tersebut secara teori mampu melayani lebih dari 2000 client secara bersamaan dalam satu waktu.

\section{KESIMPULAN}

Berdasarkan penelitian yang dilakukan maka dapat diambil kesimpulan sebagai berikut:

1. Dari hasil pengujian dengan skenario yang sama, hasil pemantauan lima pengguna yang diujikan sesuai dengan hasil perhitungan teoritis yang sesuai dengan rancangan.

2. Protokol yang digunakan berhasil dijalankan dengan baik, terbukti dengan hasil pengujian yang menunjukkan bahwa 5 dari 5 protokol yang diuji menunjukkan informasi yang sama dengan yang diinginkan pada rancangan.

3. Data pemantauan melalui smartphone dapat dibuktikan sesuai dengan hasil perhitungan teoritis atas data yang sama dengan skenario yang sama.

4. Pemantauan dari smartphone android menggunakan bandwith rata-rata $0.623 \mathrm{KBps}$, sedangkan penyimpanan ke server oleh meteran arduino menggunakan rata-rata bandwith $0.423 \mathrm{KBps}$.

\section{SARAN}

Berikut saran untuk pengembangan sistem dalam penelitian selanjutnya:

1. Menggunakan sistem dengan server sendiri atau server yang lebih baik performanya.

2. Dapat mengintegrasikan sistem meteran dengan sensor sesungguhnya.

3. Dapat mengujikan performa sistem pada keadaan yang lebih mendekati kasus nyata.

\section{DAFTAR PUSTAKA}

[1] Lutfi, M. E., 2013, Purwarupa kWh Meter Prabayar Berbasis Sensor Network, Skripsi, Jurusan Ilmu Komputer dan Elektronika FMIPA UGM, Yogyakarta.

[2] Raharjo,N.B., Widodo, T.S., dan Susanto, A. 2010, Sistem Monitoring Volume Air Pada Meteran Air PDAM Menggunakan Media Komunikasi SMS,Jurnal Penelitian Teknik Elektro, Yogyakarta.

[3] Anuruddha, T.A.S., Atsushi, M., dan Ozawa, S., 2013, Development of GPS Assisted Online $\mathrm{CO}_{2}$ Temperature Mapping System, International Journal of Emerging Technology and Advanced Engineering, Japan.

[4] Singhal, M. dan Shukla, A. 2012, Implementation of Location based Services in Android using GPS and Web Services, IJCSI International Journal of Computer Science Issues, Vol. 9, Issue 1, No 2, January 2012, India. 